to the optic nerve as possible. In any case, there is a great probability that almost half the visual field would be lost. When the angioma is to the temporal side of the optic disc-macular vision would be destroyed. Better that, however, than loss of the eye.

Several unsolved problems exist in connexion with this condition :-

(1) Is there a tendency for new angiomata to form as occurred in one case mentioned and illustrated by Elwyn ${ }^{4}$ ?

(2) Hard white exudates may be present early as in the right eye of case 1 described, long before any detachment was suspected. Are these due to haemorrhage in one whose retinal vessels are especially prone to leak?

(3) Why does retinal detachment occur when there is apparently little subretinal exudate and no hole in the retina?

\title{
BIBLIOGRAPHY
}

1. Moore. R. F,-Trans. Ophthal. Soc. U.K., Vol. LV, p: 3, 1935, Proc. Roy. Soc. Med., Vol. XXVI, p. 1036, 1932.

2. McDonald, R. and LippincotT, S. W.-Arch. of Ophthal., Vol. XX, p. 958, 1938.

3. Nicoll and Moore.-Brit. Jl. Ophthal., Vol. XVIII, p. 454, 1934.

4. ELWYN, H.-Diseases of the Retina, London, pp. 169, 177, 1948.

5. Weve, H.-Trans. Ophthal. Soc. U.K., Vol. LIX, p. 43, 1939.

6. Michaelson, I. C.-Brit. Jl. Ophthal., Vol. XXVIII, p. 522, 1944.

7. GoldmanN, H.-Ophthalmologica, Vol. XCVI, p. 90, 1938.

8. Foster, J.-Brit. Jl. Ophthal., Vol. XXXII, p. 83, 1948.

\section{VISUAL PROTECTION IN AERIAL WARFARE}

\author{
Air-Marshal P. C. Livingston
}

\section{INTRODUCTION.}

IN order that men may bear weapons with success and fortitude in modern warfare, it is necessary that they be armed, not only with equipment suitable to the occasion, but with their minds prepared for such high adventure that the capacity for imagination is locked within the lower levels of consciousness. Throughout the World War, 1939/45, personal experience records no case where a member of aircrew became obsessed by a dread of blindness through enemy action. On the contrary, the destruction of sight appeared so little feared, that difficulty was experienced in persuading personnel of the air arm to take reasonable precautions against ocular injury. This negation of the thought of blindness 
no doubt results from the acceptance of sight as a natural attribute, so much part of human structure that the catastrophe of its loss is beyond contemplation. Therefore, in the heat of action, it seems unthinkable that vision should be destroyed, leaving defenceless the combatant so afflicted. The very position of Man in the Universe signifies that the guiding hand which has led him safely through many hazards to his eventual goal, is dominated by a broadening mind reacting to impressions transmitted through the visual apparatus.

\section{General Consideration.}

In times of conflict it becomes necessary to introduce equipment aimed at the preservation of sight, without however creating a state of eye consciousness among those for whom the protective measures are intended. In lectures and demonstrations directed to this end, the audience should be regarded as containing a group of personnel who previously have given little thought to the risks to vision associated with aerial warfare, but are in fact strongly susceptible to suggestion. It becomes necessary therefore to exercise care in preserving the morale of aircrew personnel. Other difficulties occur peculiar to this branch of preventive medicine. No order exists whicn demands that aircrew personnel shall, under threat of penalty, adopt some special precaution designed for their safety. They may be called upon to carry a device with them on operational duty, but there is no guarantee as to its use. The problem becomes one of appeal to reason backed by sound argument. In this, as in so many other matters, the example set by Captains of aircraft becomes of particular significance. Aircrew are often hero worshippers. Frequently without a thought, they accept as indisputable the opinion of one well reputed for skill in combat. At times a situation so created maynot be directed to the best interests of the Service, because some pilots of high achievement are individualists whose ideas do not conform to the recognised tactics of combat. It should fall to the lot of those whose duty it is to reduce wound incidence to offer their knowledge and experience in a manner which will create a proper understanding of the situation and of the elementary principles concerned. It is well appreciated that great individualists in War are not always the most suitable guides for a population so varied in background and psychological structure as that prevailing in aircrew. These features are stressed because they reveal a number of difficulties that may impede the use of apparatus constituting part of a campaign directed against traumatic blinding. 


\section{Events Which Threaten Blindness}

Some operations of aerial warfare contain hazards common to combatant forces in general, others are peculiar to actions developing at altitude. Examples of the former are found in low level attack on enemy transport columns, railway systems or airfields. Here the defensive fire is commonly from machine guns, rifles and other light weapons.

High level operational flying draws fire from defensive weapons on the ground, such as light or heavy anti-aircraft guns and rockets, while in addition attack by machine gun or cannon fire may come from intercepting aircraft. Ocular injuries are found to occur from missiles intact, from fragments of these after explosion outside or inside the aircraft, or from shattered parts of the aircraft. Injuries of serious character are sustained through burns from fires started in fuel tanks or by the ignition of incendiary bombs carried within the aircraft. Fires following a crash on landing at base sometimes occur. A forced landing as a result of engine failure accounts for other forms of injury, as when the head strikes against projecting parts of the instrument panel, especially if the harness designed to restrain forward propulsion of the body happens to break.

Sudden structural failure of the air frame, in high speed manoeuvres, when for example portions of the engine cowling break away or a wing fractures, may terminate in severe facial injury involving the eyes. More rarely, wild fowl have been known to smash through the cabin structure and destroy vision.

The foreign bodies responsible for ocular injury sustained on flying duty may be metallic or non metallic. The metallic foreign bodies are more frequently non magnetic than magnetic. Therefore, the magnet in the extraction of these particles is of limited value. Experience tends to show that the eye is more tolerant of the presence of fragments of metallic alloys than was at first believed. An exception is copper.

Perspex, one of the cellulose acetate group of materials used in aircraft cabin windows, is fortunately very well tolerated. It sometimes occurs that twenty or more tiny pieces of perspex become embedded in the cornea and remain without serious reaction occurring. The only unpleasant sequel is the abnormal dispersion when light strikes the surfaces of these translucent foreign bodies set at varied angles in the substance of the cornea.

\section{Methods of Combating Ocular Injury}

These group themselves under three headings :

(1) Measures incorporated within the structure of the aircraft. 
(a) Bullet proof glass is constructed in layers united under pressure and held together by an adhesive substance. The glass plates so prepared attain a thickness of $1 \frac{1}{2}$ " or more. Welded steel or light alloy tubing comprise the supporting framework. Illustrations 1 and 2 show the effect produced upon the front screen of a fighter aircraft by the impact of a bullet at close range. Only a very few flakes have been detached on the side of the screen

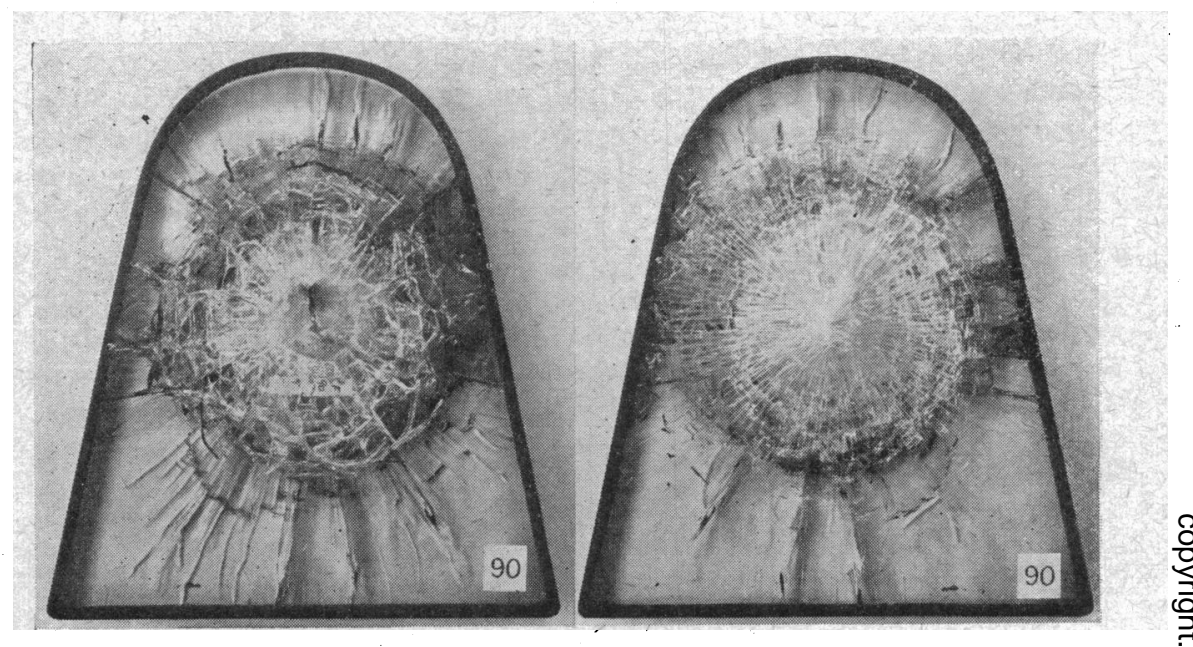

ILLUSTRATION 1.

Front surface of bullet proof glass windscreen, fighter aircraft showing effects produced by 0.303 armour piercing bullet at 200 yards.
ILLUSTRATION 2.

The same windscreen as ( 1 ), showing surface towards pilot: Note how few particles of glass have been shed from the mass of cracks.

next to the pilot. (2) This effect was produced by a $303 \mathrm{~W}$. Mark 1 armour piercing bullet with a charge giving an equivalent range of 200 yards. A further example of the resistance of bullet proof glass is illustrated (3) in the case of a bomber aircraft. This sheet was situated behind the pilot on the starboard side. The photograph is taken looking aft. The attack was made by a Messerschmitt 210 whilst the Lancaster was on a mission to Frankfurt.' The aircraft received 80 hits. Of these, two $792 \mathrm{~mm}$. armour piercing bullets from dead'astern and level, entered the rear end of the cockpit canopy on the starboard side shattering the $3^{\prime \prime}$ bullet proof slab. In this instance a cavity of approximately $\frac{3}{8}$ " deep was made in the steel defence armour, positioned behind the pilot. A further illustration (4) provides an example of the devastating effect of close range night fighter fire upon the rear turret of a bomber aircraft. Protection in respect of the 
gunner's turret is of necessity less complete than in the case of the pilot's cockpit, owing to the need to provide an observation post which permits a good area of search. There are a number of metal supports which offer secondary protection," but the fact that the turret is designed to rotate, exposes the gunner in a more vulnerable manner than is the case with other occupants of the aircraft. Furthermore, in order to obtain the best conditions of

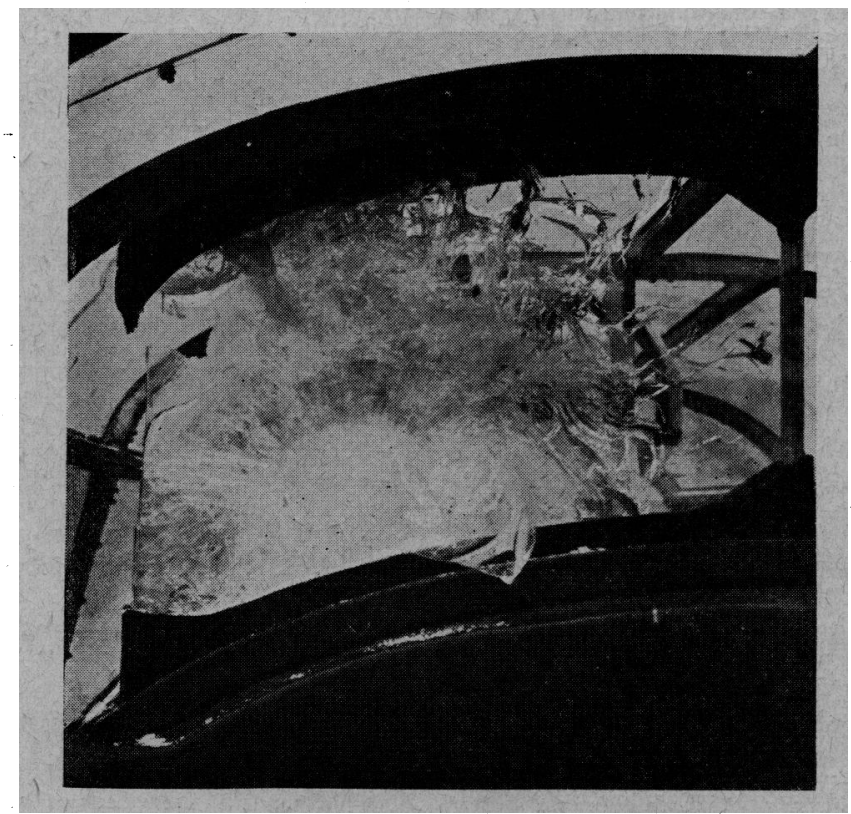

ILLUSTRATION 3.

Bullet proof glass screen situated behind pilot of Lancaster III aircraft. Effect produced by $792 \mathrm{~mm}$. armour piercing bullets.

visibility it became necessary to remove part of one of the perspex panels so as to provide an area through which search of the night sky could be made with full freedom.

(b) The use of armour is restricted by its weight. It affords excellent protection for the pilot. These plates are usually $12 \mathrm{~mm}$. thick. They can resist a $20 \mathrm{~mm}$. shell unless struck point on. Their value in visual protection is indirect. For example, they stop the flight of an explosive cannon shell, which unimpeded might come at a narrow angle from behind the pilot and exploding against the instrument panel, scatter at high velocity many particles of varied composition likely to endanger the eyes. 
(2) Equipment in the form of goggles, spectacles, visors and contact lenses worn by aircrew. (a) All safety glass used in goggles is of the laminated form, that is, two sheets of glass connected by a flexible interlayer. It will be observed, in illustration (5) d to $\mathrm{g}$, that goggle windows are composed of two surfaces meeting at an obtuse angle. This design was adopted in order to achieve great strength. It has been shown that curved safety

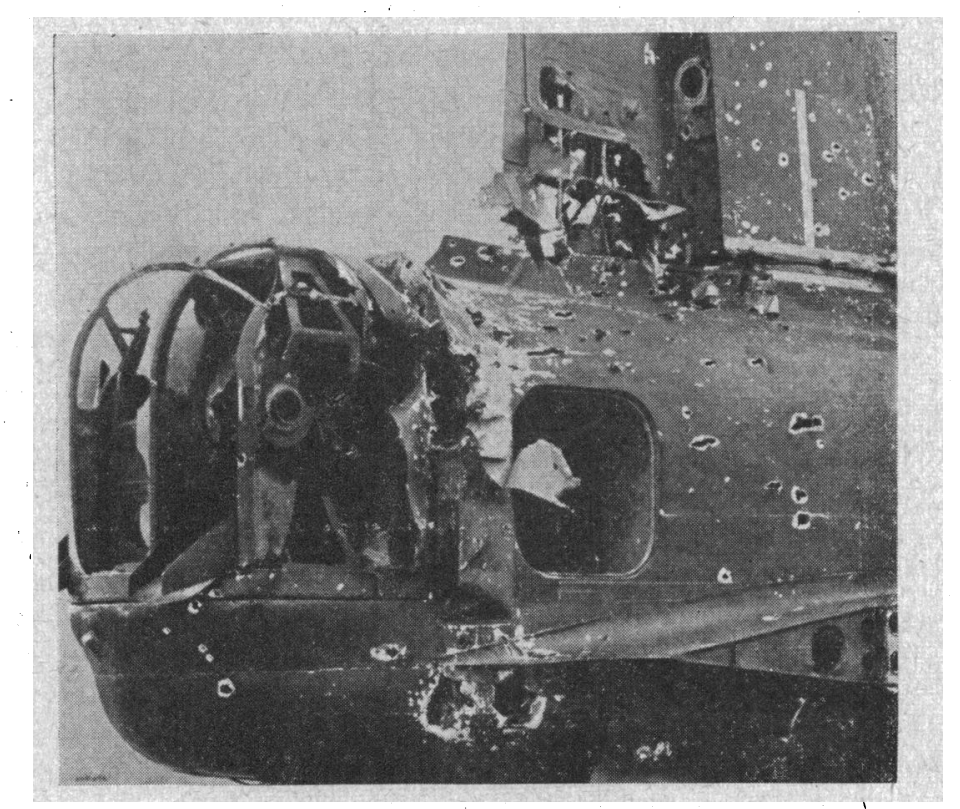

ILLUSTRATION 4.

Rear turret of Stirling aircraft after raid on Duisberg, April, 1943, showing severe damage to the rear gun turret and controls. This aircraft succeeded in reaching base.

glass as used in some types of goggle is not fully reliable. The principle of resistance to fracture is founded upon a precise union between surfaces. This union at the present time, can only be assured if the surfaces are flat. The specification under which goggle glass is passed as suitable is exacting, because the optical properties must be considered, as well as the safety factor. The test for splintering is made after accelerated ageing tests in. which the glass is subjected to low temperature, hot moist air and ultra-violet light. For the splintering test, designed to eliminate glass which on fracture has a tendency to fly, the sample is held vertically and is struck centrally on one of its faces with 
Visual Protection in AERIal Warfare



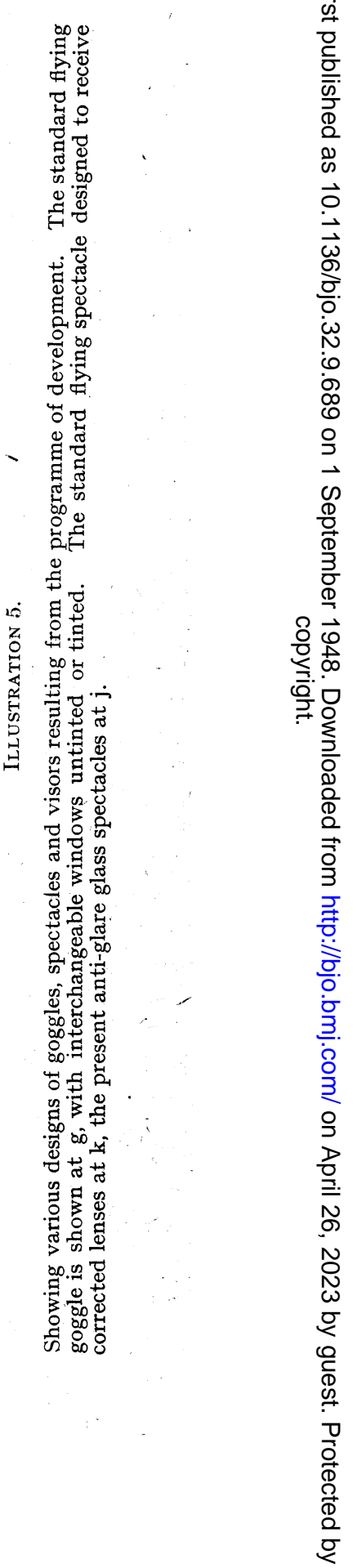


a steel ball. Fragments which may be split from the other surface are collected on a lanoline treated body placed a short distance away. The sample is rejected if splinters are found adhering to the lanoline. Great difficulties were encountered during the development of safety goggles. The design even now is not settled. Flying goggles must be light and fit comfortably. They should not become fogged during the rapid changes in atmosphere frequently encountered at high altitude. The provision of a wide field of view is an essential requirement. It is important to provide protection against fire. Finally, the goggle must be of such shape as not to interfere with the fit of the flying helmet and oxygen mask. An idea of the work of development necessary in order to attain a satisfactory appliance is expressed in illustration (5) which from $d$ to $g$ shows some of the steps in design. The weight of goggle $d$ was $7 \frac{3}{4}$ ounces, while that of goggle $\mathrm{g}$ was 4 ounces. Not only is a heavy goggle uncomfortable to wear on the ground; but it is also far more handicapping in certain manoeuvres in flight. During a sharp pull out from a dive, the weight of a goggle may, for a few seconds, be increased by as much as fixefold and become displaced. As the weight factor is extremely important, an attempt was made to distribute pressures over the head from before backwards. The results shown at illustration (5), (a) proved unstable in wind. Masks such as (b) and (c) composed of synthetic material scratch too readily. Goggles of any form are not popular in aircraft with completely enclosed cabins, but are essential in some elementary training aircraft, and also in certain fighter aircraft, when the hood is moved to the open position for take off and landing.

On occasions, a goggle has proved of value on abandoning the aircraft.

It has become necessary to provide safety spectacles of the type seen at (5), h, j and $\mathrm{k}$. The spectacles are of two types, one intended for protection against glare $(j)$, the other $(k)$ for holding corrected lenses in the case of defective visual acuity. In order to provide a field of acute vision as wide as possible, it is necessary that the frames designed to hold correction fit close to the eyes. The lenses must be ground large. The measurements of the corrected safety lenses illustrated are $44 \times 50 \mathrm{~mm}$. It is also necessary to provide a type of fitting which will maintain the spectacles in position in the presence of strong wind. The side pieces, therefore, are of metal closely applied to the sides of the head. An alternative fitting is provided which permits an elastic strap to be attached to the outside of the flying helmet.

(c) Visors made of synthetic material have been a source of experiment. Two factors, however, militate against favourable 
results ; namely the softness of the substance, thus causing a reduction in visual acuity owing to the rapid appearance of multiple scratches and the difficulty in obtaining the material suitably tinted to ward off sun glare direct or reflected. It is also to be observed that the synthetic substances of the cellulose acetate group permit the unimpeded passage of ultra-violet light in contra-distinction to the properties of glass. The advantages of visors of this character are that they are light and can readily be moulded to fit the curves of the head and the contours of equipment. Visors are illustrated at (5) b and c, with tinted shields attached.

(d) The employment of contact lenses is limited by the intolerance from ocular sensitivity, of about 60 per cent. of those who undergo preliminary trials with the shells which are employed' in the first instance. They are of great value in the few instances in which tolerance exceeds seven hours. They are strong and very resistant to fracture owing to the elasticity of the orbital content against which they are forced in the event of a blow.

(3) Methods adopted to increase visual perception.-An indirect but highly important method of aiding visual protection is to build up a system of instruction with the idea of quickening visual perception, thus raising the speed of detection and recognition of aircraft by day or night. The greatest attention has been

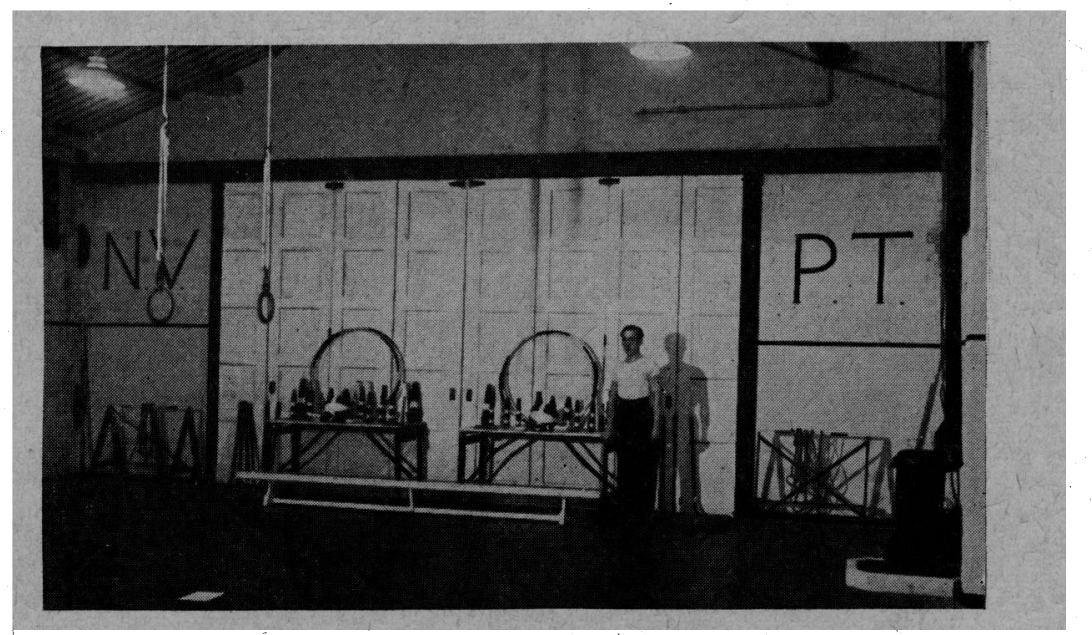

ILLUSTRATION 6.

A gymnasium used for night vision training. Note the black and white painted hoops and skittles, as well as the white trestle used in walking and balancing exercises under low illumination. 
given to improving performance under conditions of low illumination. The problem is complicated and the benefit gained is based largely upon assumption without clear statistical proof. The basis of this form of training received strong approval at Royal Air Force Headquarters, especially in Bomber Command. Fighter Command developed the technique in respect of its night fighter pilots. The aircraft were later equipped with radar for establishing contact with the enemy outside visual range. It was nevertheless essential for the human eye to establish identification. Night vision training comprises lectures upon the general principles of scanning at night time, together with practice using various devices under conditions equivalent to moonlight and starlight. Demonstrations are provided which show the effects created by altering the position of the source of night illumination upon ground targets. Games are played under low illumination in the gymnasium as illustrated in (6) with the participators wearing light trapped safety goggles containing dark filters. After a few lessons the improvement in performance is often remarkable. In the case of night interceptor pilots special care is taken to assure a high standard of night visual capacity before flying training in this branch of aerial warfare is commenced.

\section{The Assessment of Protective Measures}

In estimating the full value of the measures which have been described, it is found very difficult to establish the position on a statistical footing. So many and varied are the situations encountered in War operations, that it is hard to discover sure ground from which the true value of visual protection can be calculated. For example, a number of personnel found it impossible to wear their goggles regardless of the wide field of vision provided and the eventual comfort attained, because they experienced a feeling of restriction, however good the optical qualities of the goggle glass. Much depends upon skill in the tactics of combat in the air which applies equally to both sides. Much of this skill is founded upon experience, with which goes a greater capacity for accurate and rapid visual perception. The element of fortune tends to exercise a strong influence upon the issue. It is, in truth, only possible to institute a search for various ways of protecting the eyes against injury, to employ every one that appears practical and likely to be appreciated, to spare no pains in explaining the value of these procedures, so that the greatest number of personnel will be encouraged to make use of them, and from this position to await the issue. One positive 
approach in the campaign against blindness is the early elimination or treatment of those of doubtful visual capacity for day or night flying duties. At one time it was necessary to accept pilots with a visual acuity no better than $6 / 18$ in both eyes correctable, however, at least to $6 / 6$. To assist these personnel, over 12,000 goggles with correcting lenses were issued. The high standard of at least $6 / 6$ in one eye and not worse than $6 / 9$ in the other, was maintained for Air Gunners and Bomb Aimers. Over 200,000 tests for night visual capacity were carried out, with a rejection rate that rose to over 6 per cent. At the same time care was taken to observe personnel who were of borderline category in this respect, and have them sent to a ispecial clinic if their performance in the air at night was adversely reported by the Captain of the aircraft. In this manner, in one year, over one hundred personnel were subjected to a careful examination in which the field of night vision was studied by means of self luminous targets, and eliminating action taken when field defects were discovered. Among such personnel were those who suffered from early retinal

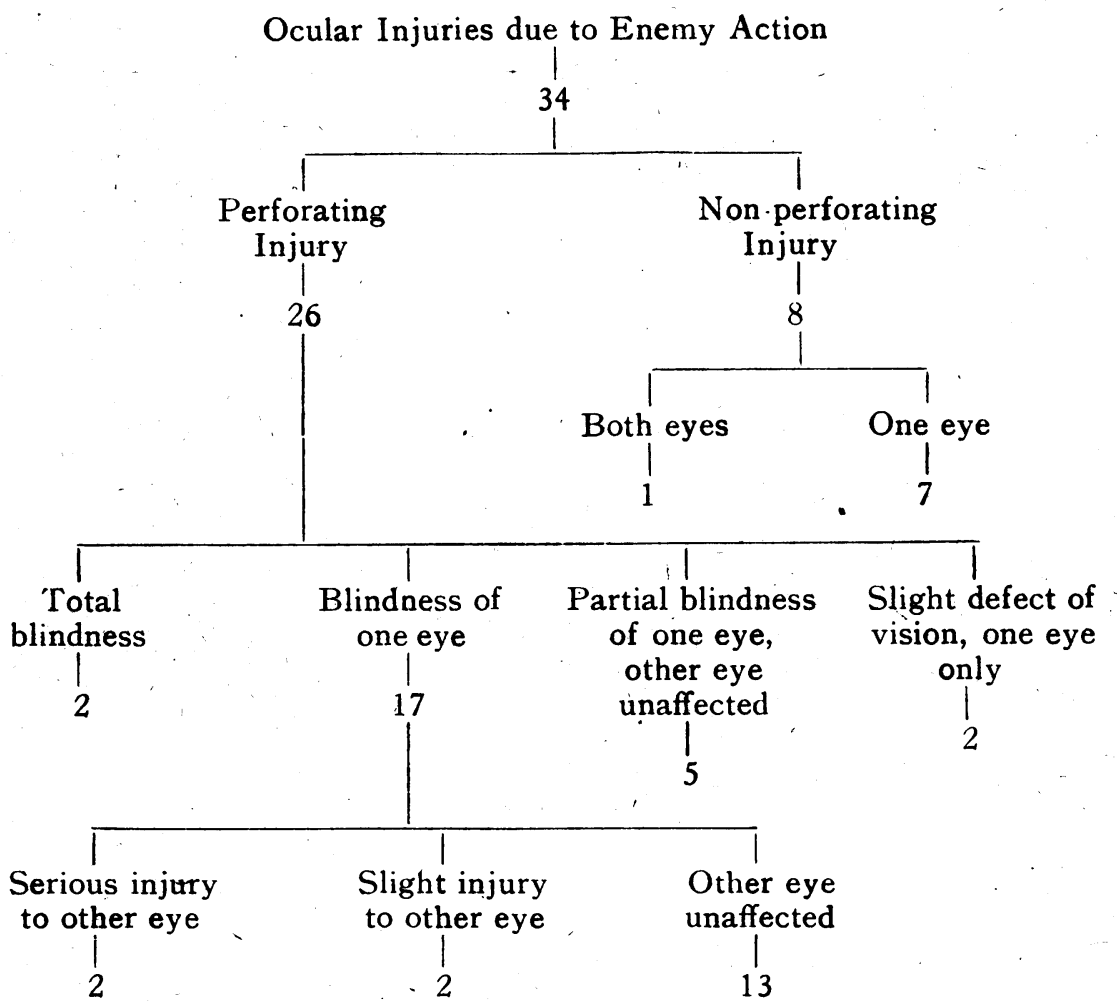


disease, or from changes reflecting themselves in the scotopic visual field, as in diabetes.

\section{The Incidence of Blindness in Air Crew Personnel in Flight}

The total loss of sight of both eyes has occurred twice only in flying operations against the enemy. The after history of one case provides a fine example of the ability of youth to surmount this catastrophic event. Entering a University he studied law and obtained honours at the graduating examination. The policy which guides such cases into the care of the St. Dunstan's organisation is, without question, right. It is here alone that a full understanding of the psychology of blindness has been mastered.

The table, p. 699, provides an analysis of the ocular injuries from Royal Air Force records, confined to air engagements with the enemy.

\section{SummaRy AND CONCLUSION}

(1) The preservation of sight can be aided by the use of bullet proof glass screens and armour plates fitted within the structure of the aircraft.

(2) Further protection can be effected by equipping aircrew with flying goggles or spectacles fitted with safety glass windows which can be ground so as to provide correction in cases of refractive error, or by fitting contact lenses in certain cases in which the refractive error cannot be otherwise adequately treated. The eyes behind contact lenses can move over a wide range without loss of acuity.

(3) Visual training offers a valuable indirect method of protection by instructing personnel in careful scanning procedure, how to make the best use of rod vision under states of low illumination, and quickening the powers of recognition of the objects detected.

(4) The record of ocular injury sustained by personnel of the Royal Air Force in flying operations lends weight to the belief that a planned campaign against the hazard of loss of sight reaps its rewards.

[Illustrations Crown Copyright Rẹserved] 